\title{
VÁRIOS
}




\section{EU TE AMO. TU ME AMAS. NÓS SOFREMOS E ASSIM MORREMOS DE E POR AMOR}

Nadiá Paulo Ferreira Universidade Estadual do Rio de Janeiro

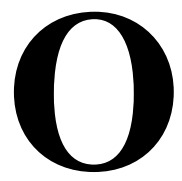

$s$ fracassos das estórias de amor e das revoluções sociais não levaram o homem à constatação de que há um impossível, o que, para a psicanálise, é o modo pelo qual o real comparece nas dimensões do imaginário e do simbólico. As frustrações, vividas como impotência do homem, conduzem à fabricação de um culpado forte e poderoso, que os escritores do século XIX identificam nas leis mercantis do Mundo, que não só corrompem a moral cristã, degradando inclusive os integrantes da Igreja, mas também causam a desigualdade entre os homens.

Os protagonistas dos romances, elevados às categorias de herói e de heroína, se tornaram símbolo da dignidade humana: a honra, enquanto atributo fálico, pertence aos homens, e a virtude, enquanto predicado feminino, pertence às mulheres. Rebeldia e resistência são os meios pelos quais esses personagens se colocam contra as leis e os limites impostos pelo Mundo, sustentando um desejo que se articula com a proibição (desejo edípico) ${ }^{1}$ e com a

${ }^{1} \mathrm{O}$ desejo faz parte da estrutura do ser falante, e, como tal, não é efeito da proibição. Estou usando desejo edípico, no sentido em que um querer só pode ser formulado sob a forma de um não que, por sua vez, se sustenta na conjunção do eu-ideal com o ideal-do-eu.

Para Lacan, o eu se constitui no registro imaginário e, portanto, está sempre investido por um ideal. O estádio do espelho corresponde ao tempo em que se constitui o eu-ideal, onde a criança apreende, pela primeira vez, a imagem unificada do seu corpo. Essa apreensão, que cativa e aprisiona o 
identificação imaginária do sujeito a um objeto, fazendo com que este adquira o valor de Bem-Supremo, e, como tal, insubstituível. Do fracasso ao mito, a literatura romântica nos mostra como a paixão do homem pela verdade transforma o sofrimento em meio de gozo. $\mathrm{E}$, justamente por isto, a premissa da união do amor com a Felicidade se declina em eu sofro, tu sofres, nós sofremos... Trata-se de uma época em que o masoquismo moral é cultivado ao ponto de a dignidade humana se tornar sinônimo de sofrimento e de expiação, fazendo com que o gosto pelas confissões seja um dos traços da literatura.

O discurso romântico incorpora a dicotomia maniqueísta cristã, que se sustenta no binômio matéria x espírito: o bem faz parte da essência do ser assim como o mal se enraíza na matéria. Esta, por ser precária, degrada o ser, e, justamente por isto, se torna tirânica. O mal está na matéria. O mal se enraíza no corpo libidinal e no corpo social. A falta original de todo falante, marcado e submetido às leis da linguagem, é negada pela crença na existência de um ser. A falta estruturante é substituída por uma essência, cujo atributo é a bondade imanente, que passa a ser degradada pelos valores mercantis do Mundo. O mito da Felicidade se sustenta na crença de um outro que, pela via do amor, realizaria o encaixe perfeito entre dois seres, fazendo Um só ser. Mas para isso é necessário que o

sujeito numa ficção imagética, será a sede de todas as identificações imaginárias em que o sujeito se aliena. É nesse sentido que Lacan diz que o eu é sempre o outro. O ideal-do-eu precede à constituição do eu-ideal, pertencendo, portanto, ao registro simbólico. No Seminário 1, os escritos técnicos de Freud, 1953-54, Lacan fala de dois narcisismos. Um que se relaciona à imagem corporal (identificação imaginária) e outro que se relaciona com a palavra (identificação simbólica): é a relação simbólica que define a posição do sujeito como aquele que vê. É a palavra, a função simbólica que define o maior ou menor grau de perfeição, de completude, de aproximação, do imaginário. A distinção é feita nessa representação entre o eu-ideal e o ideal-do-eu. O idealdo-eu comanda o jogo de relações de que depende toda a relação a outrem (LACAN, 1979, p. 165). 
amado preencha os atributos morais ofertados pelo discurso cristão. Denega-se a falta, que pertence à estrutura da espécie falante, transformando-a em contingência. O coração como metáfora se torna espelho d'alma enquanto morada de um ser. Opera-se uma conversão imaginária, corporificando o Outro, enquanto lugar excêntrico aos sujeitos, no mundo e suas leis. A transformação do sujeito em objeto faz com que os heróis e as heroínas sejam devorados ou degradados pelo Outro elevado à potência máxima.

O corpo, enquanto objeto perecível, e o Mundo, enquanto Outro onipotente, encarnam o mal, assim como o sujeito, em sua essência, porta o bem. A luta entre o Bem e o Mal é a causa do conflito perpétuo do homem consigo mesmo e com o mundo. No corpo está alojado o gozo fálico. E o mundo, transformado pelo progresso, é regido pelas leis mercantis. O corpo (matéria) e o mundo (Outro) arrastam o homem para a perdição.

No maniqueísmo romântico, a luta entre o Bem e o Mal ocorre em duas cenas: uma interior, que é o conflito que se trava entre o sujeito-suposto-ser e sua sexualidade, já que o o gozo fálico está condicionado ao amor e ao casamento; e outra exterior, que é o embate entre o eu e o mundo (Outro). Se o sujeito tem como atributo imanente o Bem, logo o que é falta significante adquire o sentido de falta moral, fazendo com que esse discurso transforme o que não há em o que deve ser conquistado. Ao nível dos objetos, não só deve ser combatido o dinheiro, como agente de corrupção, mas também as mulheres que se prostituem. Ao nível do sujeito, deve ser conquistado o amor, o Bem que traz a Felicidade. O homem, pela via do amor, encontraria o objeto do seu desejo, isto é, A Mulher. Essa crença provoca um verdadeiro horror de caráter fóbico em relação às mulheres. Toda vez que uma mulher comparece como objeto-causa do desejo de um homem, os românticos estremecem. Por quê? Exatamente nesse momento, a ficção de que o desejo deveria advir do amor é colocada em questão. E as mulheres, nessa posição, são rechaçadas e qualificadas de demoníacas. A mulher só pode ocupar o lugar de coisa amada com 
valor de agalma se encarnar o ideal da virtude. Ou seja, é necessário dessexualizá-la para que possa vestir a imagem da virgem. Só a partir daí, é que ela adquire o valor de preciosidade inaudita ou, como diziam as narrativas medievais, de maravilha. A Felicidade, enquanto valor privilegiado, vem se articular a uma carência para que se possa construir a ilusão fálica de que o amor, e só o amor, virá suprir o que falta ao ser. Mas, como não podia deixar de ser, nessa procura, surge uma barreira que irá impedir o encontro do sujeito com o seu Bem. O impossível se converte em empecilho imaginário: o Mal, que se instalou no mundo, corrompendo os homens, inviabiliza a conquista da Felicidade. Daí a importância que é dada à educação, visando à domesticação das pulsões, subordinando-as ao amor, e a transformação do mundo. A função da educação é recolocar o homem no caminho do seu bem. ${ }^{2}$ A pedagogia é o caminho não só de um resgate, mas também o que vem encarcerar o desejo, universalizandoo em metáforas com valor de verdade absoluta. Rousseau, em seu livro, Emílio ou Da Educação, partindo do pressuposto que "tudo degenera entre as mão do homem", ${ }^{3}$ assinala com todas as letras o papel fundamental da educação na reconstrução de uma ordem social baseada na Felicidade como Bem comum a todos os homens. A imposição moral vem assassinar a diferença para instaurar o reino da igualdade em nome da Liberdade e do Império dos Sentidos. Da oposição entre ser (essência) e matéria (sexualidade humana / mundo) nasce o culto da natureza, sob a via do panteísmo e do antropomorfismo. Os românticos, além da bondade original, também, acreditavam em uma tendência inata e criativa, que se manifestaria tanto ao nível individual, sob a forma da genialidade (filósofos, legisladores, homens de Estado e artistas), quanto ao nível

\footnotetext{
${ }^{2}$ V. o texto de minha autoria, "Sob os Véus da Castração - a Questão do Pai na Modernidade e na Contemporaneidade", no livro O que é um pai?, nas páginas 49 a 84, e os seguintes livros de Jean Jacques Rousseau: Emílio ou Da Educação e As Confissões.
}

${ }^{3}$ ROUSSEAU, 1995, p. 8. 
coletivo, sob a forma de espontaneidade criadora do povo. Dessa essência criadora advém outro mito do amor sob a a forma do nacionalismo.

A partir desse conflito entre o sujeito e o Mundo transformase o impossível em impotência, para que esta última se converta em sofrimento com o qual se goza. Da decepção nasce a ironia romântica, que é, ao mesmo tempo, escudo e arma do escritor. Como arma, é o instrumento para criticar a sociedade burguesa. Como escudo, é o meio para as queixas e os lamentos. O herói romântico, enquanto ideal do próprio escritor, é aquele que encontra no sofrimento o seu inferno gozante, e na ironia a sua tisana. Em momento algum a desavença entre sujeito e as leis sociais remete para a questão do mal-estar freudiano. ${ }^{4}$ Não se trata da sexualidade humana, enquanto traumática, e, muito menos do não haver o objeto do desejo. Muito pelo contrário, a concepção de amor romântica se sustenta na promessa de que há o objeto do desejo. E se há, no ponto em que amor e desejo se articulariam, o sujeito iria encontrar a tão decantada Felicidade. Trata-se de um discurso que recalca a castração pela via da denegação. Sob a forma de retorno do recalcado, o impossível se repete como aquilo que poderia ter sido mas que nunca será. E, justamente por isso, o mito da Felicidade se constrói em torno de estórias infelizes que retratam um desfilar de frustrações que conduzem ao sacrifício do sujeito. O brilho heróico do sacrifício cativa o leitor, fazendo com que a leitura se torne usufruto para seu gozo. Um ponto de ligação, pela via da comoção, é feito entre as personagens e os leitores (identificação histérica), perpetuando uma ficção que só assim pôde fazer uma escola, que reinou de forma hegemônica no século XIX. Além disso, esse usufruto de gozo do leitor se inscreve na origem de um sujeito,

\footnotetext{
${ }^{4}$ V. "O Mal Estar na Cultura" (1929/1930), de Freud, que, na edição espanhola, é traduzido por El Malestar en la Cultura.
} 
onde a entrada da função do significante - a vinda do Espírito Santo - constitui o gozo do ser falante como gozo do Outro. ${ }^{5}$

O amor está para a redenção individual assim como as reformas liberais estão para a salvação do mundo. Os ideais de Liberdade, Igualdade e Fraternidade da Revolução Frances (1789) foram escritos com sangue. Todavia os crimes praticados pelo ardor das reformas são imputados à maldade do Mundo para que se possa salvar dos escombros os ideais que, enquanto sonho irrealizável, primeiro, se apresentam como utopia, para, depois, se transformarem em melancolia.

Em Viagens da Minha Terra, o passado literário de uma nação e a fé no liberalismo são retomados para que a exaltação do amor ceda lugar à valorização do nacional. ${ }^{6}$ Nesse romance, Garrett retoma a tradição da novela de cavalaria, onde cada capítulo é introduzido por um título, que antecipa o que será narrado. Não se trata mais de um narrador onisciente, que anuncia os fatos narrados, mas sim de um artifício para que o próprio autor se apresente como personagem de ficção. Como ilustração, cito a abertura do primeiro capítulo:

${ }^{5}$ Lacan, no Seminário 4, A Relação de Objeto, se refere à vinda do Espírito Santo para indicar a inscrição de um corpo vivo nas leis da linguagem, isto é, na dimensão simbólica. Ou dito de outro modo: onde não havia nada passa haver um significante $\left(\mathrm{S}_{1}\right)$ que, como marca singular, será representado por uma série de signficantes $\left(\mathrm{S}_{2}\right)$, produzindo um sujeito cindido, porque irá se situar no intervalo desses significantes $\left(\mathrm{S}_{1}\right.$ e $\left.\mathrm{S}_{2}\right)$. De onde vem os significantes? Do Outro enquanto lugar excêntrico a todos os sujeitos falantes e, como tal, a morada dos significantes. Quem é para todo falante o primeiro representante desse Outro? A mãe e seu desejo. Justamente por isso Lacan define o desejo do homem como desejo do Outro. Assim, os cuidados maternos, desde a higiene até a alimentação, irão mapear esse corpo, produzindo nele zonas erógenas. É nesse sentido que podemos afirmar com Lacan que o gozo do ser falante se constitui como gozo do Outro. É a isto que estou me referindo, quando afirmo que o leitor experimenta uma certa satisfação (gozo) com o sacrifício heróico das personagens.

${ }^{6}$ V. o texto de Sérgio Nazar David "Almeida Garrett: sua Viagem, sua Vertigem", no livro Paixão e Revolução. 
De como o autor deste erudito livro se resolveu a viajar na sua terra, depois de ter viajado no seu quarto; e como resolveu imortalizar-se, escrevendo estas suas viagens (...). ${ }^{7}$

As viagens, em vez de uma narrativa épica, onde as aventuras do herói simbolizam os grandes feitos de um povo, visam mostrar os efeitos do progresso e as cicatrizes de um passado. Portugal é um país cuja paisagem, como se fosse uma fotografia, retém as marcas do passado, indicando o fracasso do presente. Os liberais perderam a primeira batalha e a vitória é de Sancho Pança. Mas, como Garrett não abre mão de sua crença no progresso como salvação do homem, resta a esperança nos quixotes do futuro:

(...) há dois princípios no mundo, o espiritualista, que marcha sem atender à parte material e terrena desta vida, com os olhos fitos em suas grandes e abstractas teorias, hirto, seco, duro, inflexível e que pode bem personalizar-se, simbolizar-se, pelo famoso mito do Cavaleiro de Mancha, D. Quixote; - o materialista, que, sem fazer caso nem cabedal dessas teorias, em que não crê e cujas impossíveis aplicações declara todas utopias, pode bem representar-se pela rotunda e anafada presença do nosso amigo velho Sancho Pança.

Mas, como na história do malicioso Cervantes, estes dois princípios tão avessos, tão desencontrados, andam contudo juntos sempre; ora um mais atrás, ora outro mais adiante, empecendo-se muitas vezes, coadjuvando-se poucas, mas progredindo sempre.

E aqui está o que é possível ao progresso humano.

E eis aqui a crónica do passado, a história do presente, o programa do futuro.

Hoje o mundo é uma vasta Baratária, em que domina el-rei Sancho Pança.

Depois há-de vir D.Quixote. ${ }^{8}$

O desencanto garrettiano vem acompanhado de uma ironia consigo mesmo. Como ele, outros quixotes hão de vir combater o mundo burguês e a força infernal do dinheiro. Ele, agora, confessa ao leitor, que o rebelde deu lugar ao conservador. Este romance,

${ }^{7}$ GARRETT, 1974, p. 15.

${ }^{8}$ GARRETT, 1974, p. 27-28. 
seguindo a trilha de Rousseau, em As Confissões, apresenta um compromisso com a verdade com se fosse uma profissão de fé, o que inclui a exposição de "todos os pecados":

Acha-se desapontado, o leitor, com a prosaica sinceridade do A. destas viagens. - O que devia ser uma estalagem nas nossas eras de literatura romântica. - Suspende-se o exame desta grave questão, para tratar, em prosa e verso, um mui difícil ponto de Economia política e de moral social. - Quantas almas é preciso dar ao diabo e quantos corpos se têm de entregar ao cemitério para fazer um rico neste mundo. (...) ${ }^{9}$

Não há confissão sem culpa, e Garrett se dirige ao leitor, procedimento típico do fazer romântico, para se desculpar de sua própria produção lírica:

Mas aqui é que me aparece uma incoerência inexplicável. A sociedade é materialista; e a literatura, que é a expressão da sociedade, é toda excessivamente e absurdamente e despropositamente espiritualista! Sancho, rei de facto; Quixote, rei de direito!

Pois é assim. E explica-se... É a literatura que é uma hipócrita; tem religião nos versos, caridade nos romance, fé nos artigos de jornal (...). ${ }^{10}$

Se a função da literatura é contribuir para a tomada de consciência que levaria a transformação do social, o sofrimento de amor então não faz nenhum sentido, sendo obrigação do escritor denunciar as chagas sociais do seu tempo. Aqui, Garrett antecipa uma premissa que se tornará o lema dos escritores neo-realistas.

Em Nome-da-verdade, Garrett não deixa de criticar os escritores românticos que descambam para o sentimentalismo folhetinesco, tendo como visada agradar ao novo público burguês. A submissão do escritor à demanda de um público, ávido de aventuras e intrigas de amor, coloca em cheque a própria noção de liberdade, tão cara ao escritor romântico. Garrett escolhe denunciar

9 GARRETT, 1974, p. 34.

${ }^{10}$ GARRETT, 1974, p. 38. 
a si mesmo e aos seus pares, porque insiste em se agarrar à idéia de que a literatura tem uma função importante nas revoluções sociais. Hoje, dir-se-ia que Garrett julga em nome de uma posição "politicamente correta".

O discurso da liberdade se sustenta no direito do indivíduo à autonomia e à independência absoluta. Essa aspiração, que faz parte dos mitos de nosso tempo e tem como herança o iluminismo, pode ser comparada, "em todos os pontos, a um discurso delirante", ${ }^{11}$ já que esta autonomia irredutível implica retirar de cena a função paterna.

O sentido de liberdade, associado aos ideais de autonomia e de autenticidade, produz outro mito romântico, que é a noção de originalidade, onde vamos encontrar a mais radical anulação do Outro como lugar excêntrico aos seres falantes e da linguagem. Esta anulação, excludente da metáfora paterna, faz com que um dos traços dos romantismo seja o delírio. Não estou afirmando que os escritores românticos são psicóticos. Isso, inclusive, seria uma grande asneira. Estou dizendo que o discurso, produzido pelos românticos, aponta para alguns elementos que fazem parte de duas estruturas: a paranóica e a neurótica. O compromisso obstinado com a verdade é um traço paranóico. Já o desejo se inscreve numa estrutura neurótica, como já assinalei em outro escrito, ${ }^{12}$ onde desejar se torna sinônimo de dizer não a uma ordem que se apresenta na contramão ao caminho que conduziria à Felicidade.

A grande crítica de Garrett a cultura portuguesa está centrada na falta de originalidade da literatura portuguesa romântica:

Todo o drama e todo romance precisa de:

Uma ou duas damas,

Um pai,

Dois ou três filhos de dezanove a trinta anos,

Um criado velho,

\footnotetext{
${ }^{11}$ LACAN, 1985, p. 154.

${ }^{12}$ V. "Sob os Véus da Castração - a Questão do Pai na Modernidade e na Contemporaneidade", que se encontra no livro O que é um pai?
} 
Um monstro encarregado de fazer as maldades,

Vários tratantes e algumas pessoas capazes para intermédios.

Ora bom; vai-se aos figurinos franceses de Dumas, de Eugénio Sue, de Vitor Hugo, e recorta a gente, de cada um deles, as figuras que precisa; guarda-as sobre uma folha de papel de cor da moda, verde, pardo, azul - como fazem as raparigas inglesas aos seus álbuns e scrapbooks; forma com elas os grupos e situações que lhe parece; não importa que sejam mais ou menos disparatados. Depois vai-se às crónicas. Tiram-se uns poucos de nomes e palavrões velhos; com os nomes crismam-se os figurões; com os palavrões iluminam-se... (estilo de pintor pinta-monos). E aqui está como nós fazemos a nossa literatura original!13

Essa crítica, feita em nome da originalidade, implica em considerar o romantismo português um plágio do romantismo francês. Não se pode negar a influência deste naquele. Mas a questão é que o plágio não existe. No campo do Outro não há proprietários dos significantes. Eles estão lá, à disposição de qualquer falante. Cada um se apropria dos significantes que quiser para com eles operar certas articulações, produzindo um discurso que sempre levará a marca de um sujeito, nem que esta seja tomar como modelo o discurso de outro. Nesta instrumentalização do significante por ação de um sujeito, algumas metáforas novas podem ser produzidas ou não. Um discurso ou cria uma nova sintaxe ou reproduz uma sintaxe já estratificada. Em ambos os casos, a cópia enquanto reprodução fotográfica não existe, o que existe é repetição. Mas nesta há sempre algum significante que receberá um determinado acento em sua posição com os outros, indicando, ali, a presença de um sujeito.

Para Garrett, em suas viagens, os frades foram aliados dos reis assim como os novos burgueses são aliados do poder republicano. Mas como ele não pode sentir saudades da monarquia, sente saudades do que os frades poderiam ter sido e ter feito, mas nem foram nem fizeram. Aliás isso é dito, literalmente:

13 GARRETT, 1974, p. 50-51. 
Quando me lembra tudo isto, quando vejo os conventos em ruínas, os egressos a pedir esmola e os barões de berlinda, tenho saudades dos frades - não dos frades que foram, mas dos que podiam ser. ${ }^{14}$

A crítica garrettiana do social se assemelha muito com a visão de Balzac: no mundo presente o novo rei é o dinheiro. Com ele se compra até a dignidade humana. O autor-narrador se divide entre o que esperava ter acontecido com a revolta liberal e o que está acontecendo. Assim, nessas viagens, alternam-se os momentos saudosistas de um passado recente e as frustrações com o presente. Entre Cartaxo e o Vale de Santarém, a beleza da vasta planície e o delicioso aroma selvagem da charneca, exatamente, ali, vem a lembrança de seu passado de lutas:

De repente, acordou-me do letargo uma voz que bradou:

- Foi aqui!... aqui é que foi, não há dúvida.

- Foi aqui o que?

- A última revista do imperador.

- A última revista! Como assim, a última revista!... Quando? Pois? Então caí completamente em mim e recordei-me, com amargura e desconsolação, dos tremendo sacrifícios a que foi condenada esta geração... Deus sabe para quê; Deus sabe se para expiar as faltas de nossos passados, se para comprar a felicidade dos nossos vindouros... ${ }^{15}$

De quem é a culpa, já que se trata de um imperativo? É preciso se eleger pelo menos um ou alguns para que haja isenção dos outros. Para o escritor, são os frades, denunciados com veemência nas Viagens, Mas eles não são os únicos, há também os barões. Esses são piores do que os frades: "Nós também errámos em não entender o desculpável erro do frade, em lhe não dar outra direcção social e evitar assim os barões, que é muito mais daninho bicho e mais roedor". ${ }^{16}$

\footnotetext{
${ }^{14}$ GARRETT, 1974, p. 118.

15 GARRETT, 1974, p. 81-82. O grifo é meu.

${ }^{16}$ GARRETT, 1974, p. 118.
} 
O progresso está afastando o homem de Deus, da virtude, da contemplação da natureza e está, também, corroendo as esperanças românticas de um novo mundo. As viagens de Garrett revelam a sua frustração com o novo mundo que ele mesmo ajudou a criar, pegando em armas. Lembra-se dos combates, onde assistiu à morte de muitos homens ("Toda a guerra civil é triste") 17 Mais melancólico, ainda, fica, quando constata que não está acontecendo nenhuma mudança. A viagem representa, também, o lamento com o que poderia ter sido. Não há nesse mundo desencantado lugar para os escritores, só há lugar para os bonapartes e para os rothschilds. Mandar com a espada e comprar com o dinheiro é como o mundo se apresenta ao seu olhar deceptivo.

No capítulo XII, aparece a figura feminina da Joaninha, que não tinha a formosura da rosa, mas encarnava a pureza angelical do lírio, paradoxo em torno do qual o objeto feminino é abordado em sua lírica: "Joaninha não era bela, talvez nem galante sequer, no sentido popular e expressivo, que a palavra tem em português... mas era o tipo da gentileza, o ideal da espiritualidade". ${ }^{18}$ Joaninha, como paradigma da heroína romântica, não só faz "juras de amor" como as cumpre até a morte. O primo Carlos foi o seu primeiro, único e verdadeiro amor. Mas o seu amado irá se corromper e passar para o lado dos barões.

A partir do capítulo XXIV, será narrado como Carlos, tendo como ancestral o Adão natural irá se transformar no Adão social. $\mathrm{Na}$ construção dessa personagem, é reproduzida a dicotomia rousseauniana entre a bondade originária (natureza humana) e a maldade do mundo (natureza social). O homem, feito a imagem de Deus, e, por isso, bom em sua essência, converte-se em um aleijão moral. A passagem de um estágio a outro é feita de forma que fique bem demonstrada a impotência do homem diante da potência do mundo. Diz o narrador:

${ }^{17}$ GARRETT, 1974, p. 82.

18 GARRETT, 1974, p. 106. 
Demais, cada tentativa nobre, cada aspiração elevada de sua alma, lhe tinha custado duros castigos, severas e injustas condenações desse grande juiz hipócrita, mentiroso e venal... o mundo.

Carlos estava quase como os mais homens... ainda era bom e verdadeiro no primeiro impulso de sua natureza excepcional; mas a reflexão descia-o à vulgaridade da fraqueza, da hipocrisia, da mentira comum.

Dos melhores era, mas era homem. ${ }^{19}$

Carlos amou Georgina, Júlia, Laura e foi amado por Joaninha. Como o autor, acabou recebendo um título de nobreza e ingressou para o mundo dos barões.

Joaninha, miragem que encarna a versão romântica d'A Mulher, enquanto representante do Outro sexo, vai "ser anjo, na presença de Deus". ${ }^{20}$ Aqui reencontramos o paradoxo da lírica garrettiana: as mulheres que são desejadas e não são amadas, e a mulher que ama e é amada, mas, justamente por isso, só pode se apresentar como objeto impossível. Entre a miragem angelical e as mulheres, Carlos ficou com o gozo fálico de suas aventuras e com o gozo, que não passa pelo sexual, extraído do sacrifício sem heroísmo. O moralismo garrettiano inclui entre as indignidades de Carlos a sua opção pelas mulheres e pelo gozo fálico. Mas, em função dessa escolha, a personagem se vê na obrigação de renunciar ao sem bem de amor. Essa renúncia se apresenta irreversível, na medida em que o objeto de sua Felicidade irá se deslocar para um não-lugar, a fim de que a utopia venha tomar o lugar da falta com a função de denegar a castração. Assim, a falta, enquanto representante de uma ausência, se transforma em erro (pecado) para que o personagem passe a viver atormentado pelo sentimento de culpa. Sem medicamento para essa dor, o único analgésico que pode aliviar o sofrimento é utopia.

Se Garrett já criticou os romances açucarados que descambam para o sentimental, isso não significa que o melodrama esteja ausente desse romance. Em determinado momento, o frei Dinis, agonizante, irá confessar que é o pai de Carlos:

${ }^{19}$ GARRETT, 1974, p. 196.

${ }^{20}$ GARRETT, 1974, p. 324. 
(...) Aqui está o assassino de tua mãe, de seu marido, de teu tio... o algoz e a desonra de tua família toda. - Faze de mim como for da tua vontade. Sou teu pai...

- Meu pai!... Misericórdia, Meu Deus!

- Misericórdia, filho, e perdão para teu pai! ${ }^{21}$

O manuscrito e o documento são substituídos pelas cartas. E o autor-narrador das viagens, ao tomar conhecimento de que Joaninha já havia morrido, recebe das mãos do frei Dinis as cartas que Carlos lhe enviou. Nessas cartas vamos encontrar o drama do amor, encenado por Garrett em suas poesias. Carlos diz, em uma dessas cartas para Joaninha, que há três tipos de mulheres: "a mulher que se admira, a mulher que se deseja e a mulher que se ama". ${ }^{22} \mathrm{Em}$ outra carta, Carlos, tal qual Garrett no poema "Não te Amo", confessa que o drama que o consome é ter abdicado do amor "puro e verdadeiro", que lhe era oferecido por Joaninha, e se rendido aos "amores mundanos" com Júlia, Laura e Georgina.

$\mathrm{OH}$ ! eu sou um monstro, um aleijão moral, deveras... ou não se sei o que sou!

(...) Joana, minha Joana, minha Joaninha querida, anjo adorado da minha alma, tem compaixão de mim, não me maldigas. Não quero que me perdoes, nem tu nem ninguém, que o não mereço... mas que tenhas dó e lástima de mim.

(...) Sabia que era monstro, não tinha examinado, por partes, toda a hediondez das feições que me reconheço agora.

Tenho espanto e horror de mim mesmo! ${ }^{23}$

(...) se eu ainda tivera coração para te dar, se a minha alma fosse capaz, fosse digna de juntar-se com essa alma de anjo que em ti habita. (...)

Não quero, não posso, não devo amar a ninguém mais.

(...) eu que farei? Creio que me vou fazer homem político, (...).

${ }^{21}$ GARRETT, 1974, p. 270.

22 GARRETT, 1974, p. 329.

${ }^{23}$ GARRETT, 1974, p. 344. 

$\operatorname{adeus}^{24}$

Adeus, minha Joana, minha adorada Joana, pela última vez,

Carlos abdica do amor puro e verdadeiro, ingressa na política e se torna barão. Georgina, que era rica, funda um convento na Inglaterra e vira abadessa. Joaninha vai para o céu...

Sem os tradicionais obstáculos romanescos que impedem o casamento dos amantes, Garrett explicita, ao nível do enunciado, o drama da paixão romântica: Carlos foi seduzido pelo gozo fálico, abdicou do amor e se corrompeu nos liames da vida pública. Ao nível da enunciação, temos o Garrett melancólico da lírica, onde vamos encontrar a verdadeira causa de sua desesperança: não renunciar a posição de falo, tão bem explicitada no conjunto de poemas intitulado "Ela". Carlos, como imagem especular do próprio autor, confessa que, por ter se visto como objeto do desejo materno e por não renunciar a essa posição fantasmática, só lhe resta como saída o lamento de ter perdido o que nunca foi mas que acredita ter sido um dia: objeto de um amor primeiro, Único, derradeiro. Os mesmos atributos, envolvendo a figura materna em "Ela", são retomados por Garrett, em sua lírica, para representar o objeto amado idealizado: "anjo, frente anuviada, c'roa nevada das alvas rosas do céu". ${ }^{25}$ Em oposição a este objeto, investido das qualidades maternas, vão surgir as mulheres. Desta dicotomia surgem os atributos femininos, dispostos, simetricamente, por um paradigma constituído de antíteses: anjo caído x anjo celestial; chama x luz; seio ardente e nu x véu encobridor; olbos negros, cor de noite sem estrela $\mathrm{x}$ olhos verdes de Joaninha; rosa $\mathrm{x}$ lírio, etc.

O destino de Carlos é traçado por Garrett em sua lírica: (...) "Sou, fui... escrito / Está que sou: que fui, que era já dela. / Desde que há ser em mim”. ${ }^{26}$ Quem é o agente deste destino, senão o olhar

\footnotetext{
${ }^{24}$ GARRETT, 1964, p. 355-356.

${ }^{25}$ Ver o poema "Anjo És" de Almeida Garrett.

${ }^{26} \mathrm{~V}$., no conjunto de poemas intitulado "Ela", o poema X.
} 
sustentado pelo desejo da Mãe, fazendo com que ele se veja neste lugar? O desejo da Mãe (Outro) é o seu desejo.

Acordar deste sonho implica sempre em frustração. Em Garrett a decepção dá lugar ao sentimento de culpa, que se transforma em dor, que se infinitiza em gozo, que sepulta o pulsar do desejo, que arrasta o sujeito para morte...

\section{Referências Bibliográficas}

FREUD, Sigmund. Obras completas. 3. ed. Madrid: Biblioteca Nueva, 1973. $3 \mathrm{v}$.

GARRETT, Almeida. Folhas caídas e outros poemas. 4. ed. Lisboa: Livraria Clássica Editora, 1978. (Col. Clássicos Portugueses Trechos Escolhidos, Século XIX. Poesias).

GARRETT, Almeida. Viagens da minha terra. 4. ed. Lisboa: Livraria Popular, 1974.

LACAN, Jacques. O seminário, livro 1, os escritos técnicos de Freud. Rio de Janeiro: Zahar, 1979.

LACAN, Jacques. O seminário, livro 3, as psicoses. Rio de Janeiro: Zahar, 1985.

LACAN, Jacques. O seminário, livro 4, a relação de objeto. Rio de Janeiro: 1995.

DAVID, Sérgio Nazar (coord.). O que é um pai. Rio de Janeiro: EdUERJ, 1997. (Col. Clepsidra 2).

DAVID, Sérgio Nazar (coord.). Paixão e Revolução. Rio de Janeiro: EdUERJ, 1996. (Col. Clepsidra 1).

ROUSSEAU, Jean Jacques. As confissões. Rio de Janeiro: Edições de Ouro, 1965.

ROUSSEAU, Jean Jacques. Emílio ou a educação. São Paulo: Martins Fontes, 1995. 


\section{Resumo}

Os escritores do século XIX inventaram um culpado forte e poderoso para continuar acreditando no mito da Felicidade, quer como projeto político quer como dádiva do amor. A fé nesse ideal, cujas raízes se encontram no Iluminismo, determinou não só o engendramento de um desejo, que se manifesta sob a forma de um não a ordem constituída, mas também uma postura melancólica. Assim, o sofrimento se transforma em meio de gozo, dando lugar ao sentimento de culpa ou ao sacrifício heróico. A leitura de Viagens da minha terra, visa demonstrar o caráter paradigmático desse romance, na medida em que Almeida Garret ilustra todos os impasses do homem que acreditou e apostou nos ideais de sua época.

\section{Abstract}

Nineteen century writers found out a strong and powerful feeling of guilty to keep trusting the myth of happiness, both as a political project or a gift of love. Faith on this ideal, who roots come from Iluminism, determine the building of desire, expressed by denying a stablished order, but also a melancholical position. Due to it, suffering turns into a way of having pleasure, also dealing with guilt and heroical posture. By reading the novel Viagens da minha terra, one can perceive it's paradigmatic aspect since Garret listed and ilustrated all corners man, at his time, believed and was driven into. 